Proc. Indian Acad. Sci. (Chem. Sci.), Vol. 105, No. 6, December 1993, pp. 393-397.

(C) Printed in India.

\title{
Heterogeneous and homogeneous photoassisted wastewater treatment
}

\author{
G RUPPERT ${ }^{* 1}$, K HOFSTADLER $^{1}$, R BAUER $^{1}$ and G HEISLER ${ }^{2}$ \\ ${ }^{1}$ Institute of Physical Chemistry, Technical University of Vienna, Getreidemarkt 9, A-1060 \\ Wien, Austria \\ ${ }^{2}$ Austrian Energy and Environment, SGP/Waagner-Biró GmbH, Siemensstr. 89, A-1210 \\ Wien, Austria
}

\begin{abstract}
Photochemical degradation of 4-chlorophenol (4-CP) as a model wastewater contaminant with three methods: $\mathrm{UV} / \mathrm{TiO}_{2}, \mathrm{UV} / \mathrm{H}_{2} \mathrm{O}_{2}$ and $\mathrm{UV} / \mathrm{TiO}_{2} / \mathrm{H}_{2} \mathrm{O}_{2}(\lambda>310 \mathrm{~nm})$ has been investigated and compared to the dark Fenton reaction and to direct photolysis. A UV-irradiated combination of $\mathrm{TiO}_{2}$ and $\mathrm{H}_{2} \mathrm{O}_{2}$ was found to be the most effective degradation method for TOC (total organic carbon). 4-CP was degraded most rapidly by the dark Fenton reaction. In the heterogeneous process on illuminated $\mathrm{TiO}_{2}$ without $\mathrm{H}_{2} \mathrm{O}_{2}$, only small amounts of by-products were formed during irradiation in contrast to homogeneous processes where $\mathrm{H}_{2} \mathrm{O}_{2}$ was involved. During $\mathrm{UV} / \mathrm{H}_{2} \mathrm{O}_{2}$ and Fenton experiments, coloured by-products appeared during irradiation and degradation rates of 4-CP and TOC showed strong differences between homogeneous and heterogeneous processes.
\end{abstract}

Keywords. Wastewater treatment; photooxidation; hydroxyl radicals; titanium dioxide; Fenton reaction.

\section{Introduction}

Chemical oxidation of organic contaminants in wastewater is an effective method to remove pollutants without further environmental problems. In contrast to other wastewater treatment methods, e.g. adsorption on activated granular carbon or air stripping, the contaminants are converted to harmless materials such as carbon dioxide and inorganic salts. Various processes suggested for oxidation of organic compounds are UV-photolysis in the presence of $\mathrm{H}_{2} \mathrm{O}_{2}[(1)]$ or ozone, photolysis on UV-irradiated $\mathrm{TiO}_{2},(3)+(4)$, and on the system $\mathrm{Fe}^{2+} / \mathrm{H}_{2} \mathrm{O}_{2}$ (Fenton reaction, (2). The active species in all photochemical processes is the hydroxyl radical (Haag and Yao 1992), a strong oxidant with an oxidation potential of $2.8 \mathrm{~V}$. It is generated, e.g., by the following reactions (Carey 1990):

(a) homogeneous

or

$$
\mathrm{H}_{2} \mathrm{O}_{2}+h v \rightarrow 2 \mathrm{OH}^{\cdot}(\lambda<400 \mathrm{~nm})
$$

$$
\mathrm{Fe}^{2+}+\mathrm{H}_{2} \mathrm{O}_{2} \rightarrow \mathrm{Fe}^{3+}+\mathrm{OH}^{-}+\mathrm{OH} \text {. }
$$

(b) heterogeneous

$$
\begin{aligned}
& \mathrm{TiO}_{2}+h v \rightarrow e^{-}+p^{+}(\lambda<400 \mathrm{~nm}), \\
& p^{+}+\mathrm{OH}^{-} \rightarrow \mathrm{OH} .
\end{aligned}
$$

\footnotetext{
* For correspondence
} 
In this work, the degradation of 4-chlorophenol $\left(4-\mathrm{CP}, 1.01 \times 10^{-3} \mathrm{~mol} / 1=72.9 \mathrm{ppm}\right.$ TOC) and of TOC (total organic carbon) by photochemical methods with $\mathrm{UV} / \mathrm{H}_{2} \mathrm{O}_{2}$, $\mathrm{UV} / \mathrm{TiO}_{2}$, and $\mathrm{UV} / \mathrm{TiO}_{2} / \mathrm{H}_{2} \mathrm{O}_{2}$, has been studied. The results were compared to the dark Fenton reaction, and to photolysis without additives.

Chlorophenols are widely used in the manufacture of herbicides and fungicides. Their traces were found in ground water but also in drinking water (caused by the disinfection of phenolic waters with chlorine). Because of their low biodegradability, chemical methods for the removal of chlorophenols have been developed. Degradation of chlorophenols (with low substrate concentrations) using UV-photolysis (Yasuhara et al 1977), UV-illuminated $\mathrm{TiO}_{2}$ (Matthews 1987), UV-photolysis with $\mathrm{H}_{2} \mathrm{O}_{2}$-addition (Moza et al 1988) and Fenton's reagent (Barbeni et al 1987) was reported elsewhere.

\section{Experimental details}

4-Chlorophenol (4-CP, reagent grade, Merck), $\mathrm{TiO}_{2}$ (Degussa $\left.\mathrm{P} 25\right), \mathrm{H}_{2} \mathrm{O}_{2}(30 \%$, p.a., Riedel de-Haën) and $\mathrm{FeSO}_{4} \cdot 7 \mathrm{H}_{2} \mathrm{O}$ (p.a., Merck) were used without further purification.

All experiments were performed at an initial $p \mathrm{H}$ of 5.8 in a three-necked-2l flask equipped with a plane glass window (Duran, irradiated area $3300 \mathrm{~mm}^{2}$ ) and thermostatted at $25^{\circ} \mathrm{C}$. The initial concentration of $4-\mathrm{CP}$ was $1.01 \times 10^{-3} \mathrm{~mol} / 1$ (=72.9 ppm TOC). A $400 \mathrm{~W}$ high pressure $\mathrm{Hg}$-lamp (Osram Ultramed) with quartz optics and water filter was used as light source. The solution $(2000 \mathrm{ml})$ was stirred and purged with pure oxygen during the reaction. Concentration of $\mathrm{TiO}_{2}$-suspension was $2 \mathrm{~g} / \mathrm{l}$, molar excess of $\mathrm{H}_{2} \mathrm{O}_{2}$ was $10: 1$ or $50: 1$ in comparison to 4-CF, concentration of $\mathrm{Fe}^{2+}$ in the Fenton experiment $2.5 \times 10^{-4} \mathrm{~mol} / 1$. 4-CP was analysed by HPLC (column: Spherisorb S5 ODS $50 \mu \mathrm{m}$, eluent: methanol: $\mathrm{H}_{2} \mathrm{O}=40: 60 \mathrm{Vol} \%$, flow: $1 \mathrm{ml} / \mathrm{min}$ ), TOC was monitored with a TOC analyser (Shimadzu). $\mathrm{H}_{2} \mathrm{O}_{2}$ was determined by a modified iodometric method (Greenberg et al 1985).

\section{Results and discussion}

The difference between heterogeneous and homogeneous reaction mechanisms can be explained by comparing degradation of 4-CP and TOC (figures $1 \& 2$ ). Degradation curves of 4-CP and TOC in the $\mathrm{UV} / \mathrm{TiO}_{2}$ and $\mathrm{UV} / \mathrm{TiO}_{2} / \mathrm{H}_{2} \mathrm{O}_{2}$ experiments show a similiar course, in contrast to homogeneous reactions, where the 4-CP concentration decreases more rapidly than TOC-concentration. During the dark Fenton reaction, 4-CP disappears rapidly within a few minutes but TOC removal is only $42 \%$ after 24 hours. With photolysis in the presence of a 10:1 excess of $\mathrm{H}_{2} \mathrm{O}_{2}, 4-\mathrm{CP}$ is completely degraded after 24 hours with a TOC reduction of only $51 \%$. A very high excess of $\mathrm{H}_{2} \mathrm{O}_{2}$ reduces the degradation rates of both 4-CP and TOC because of recombination of the hydroxyl radicals (Carey 1990).

In case of $\mathrm{UV} / \mathrm{TiO}_{2}$, the pollutant has to be adsorbed before reaction. This explains the low degradation rate of 4-CP. In solution, there are more free substrate molecules and more $\mathrm{OH}$-radicals for reaction, therefore 4-CP concentration in homogeneous processes decreases very rapidly. Hydroxyl radicals are able to attack the molecules without steric restrictions in contrast to the 4-CP molecule adsorbed on the 


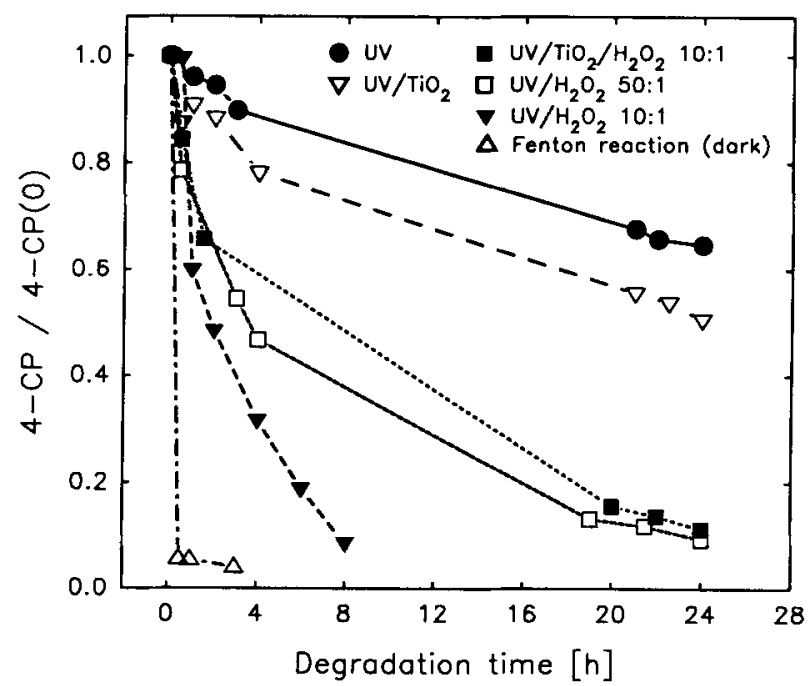

Figure 1. Degradation of 4-chlorophenol $(1.01 \mathrm{mmol} / \mathrm{l}=72.9 \mathrm{ppm}$ TOC) with different homogeneous and heterogeneous methods.

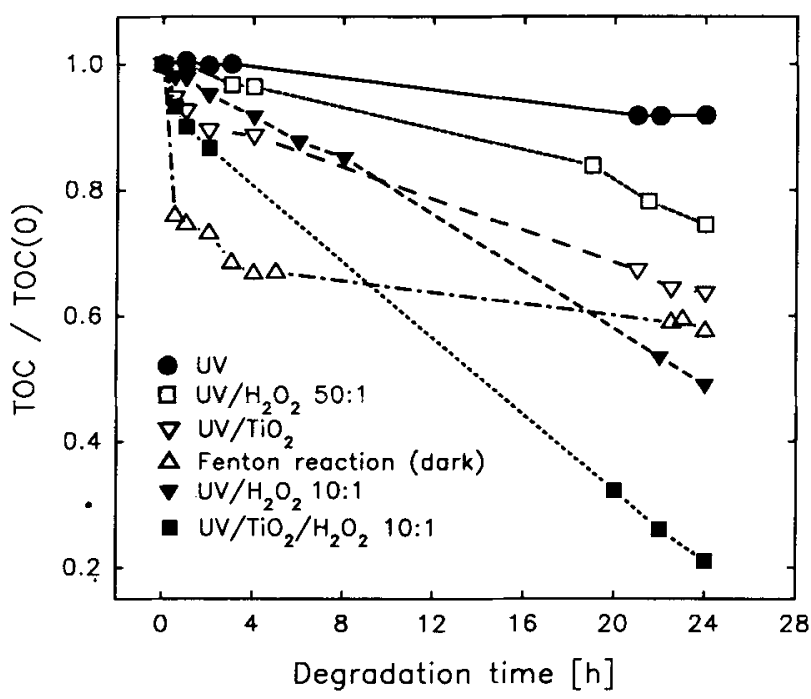

Figure 2. Degradation of TOC $(72.9 \mathrm{ppm}=1.01 \mathrm{mmol} / \mathrm{/} \mathrm{4-CP})$ with different homogeneous and heterogeneous methods.

$\mathrm{TiO}_{2}$-surface. In this case, a molecule has to be degraded nearly completely to $\mathrm{CO}_{2}$ and to desorb before a new molecule can take its place. Therefore, the amount of by-products formed during the heterogeneous process is small compared to Fenton's reagent or $\mathrm{UV} / \mathrm{H}_{2} \mathrm{O}_{2}$. Among the described wastewater treatment methods, the system $\mathrm{UV} / \mathrm{TiO}_{2} / \mathrm{H}_{2} \mathrm{O}_{2}$ combining homogeneous and heterogeneous reactions, was found to be the best degradation method for TOC. TOC degradation was about $80 \%$ after 24 hours.

In all processes degradation of $\mathrm{H}_{2} \mathrm{O}_{2}$ (figure 3) follows the curves of TOC degradation (figure 2). The most rapid decrease of $\mathrm{H}_{2} \mathrm{O}_{2}$ was observed with Fenton's reagent. 


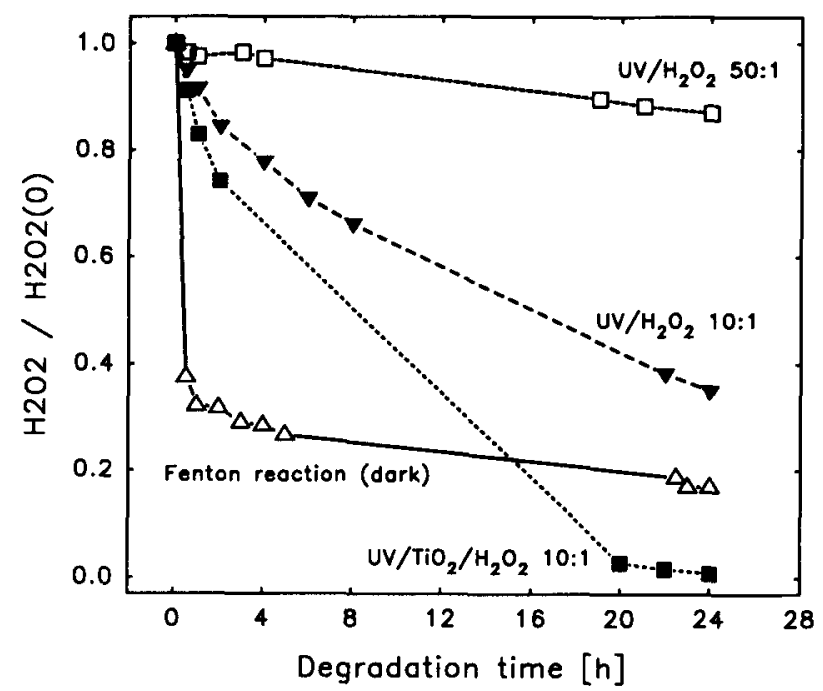

Figure 3. Decrease of $\mathrm{H}_{2} \mathrm{O}_{2}$ during reaction.

After one hour, the reaction retards because of complete oxidation of $\mathrm{Fe}^{2+}$ to $\mathrm{Fe}^{3+}$, (2). $\mathrm{Fe}^{3+}$ can be re-reduced during excitation with visible light $(\lambda<580 \mathrm{~nm})$ (Ruppert and Bauer 1993). The presence of $\mathrm{TiO}_{2}$ in the $\mathrm{UV} / \mathrm{H}_{2} \mathrm{O}_{2}$ process accelerates the degradation of $\mathrm{H}_{2} \mathrm{O}_{2}$.

For industrial use, homogeneous processes like UV/ $\mathrm{H}_{2} \mathrm{O}_{2}$ (Hager 1990) and UV/ ozone (Kearney et al 1984) are preferred to heterogeneous processes because of higher degradation rates and no separation problems with the catalyst. In recent years, reactors with immobilized $\mathrm{TiO}_{2}$ have been developed to avoid this problem (Al-Ekabi and Serpone 1988; Hofstadler 1992; Hofstadler et al 1992).

Indeed, photochemical oxidation is an effective way to destroy organic water pollutants although the process has to be optimized and adapted to the contaminant and its concentration.

\section{Acknowledgements}

The authors would like to thank the FFF (Forschungsförderungsfonds der Gewerblichen Wirtschaft Österreichs, P 3/8669) for their financial support.

\section{References}

Al-Ekabi H and Serpone N 1988 J. Phys. Chem. 925726

Barbeni M, Minero C and Pelizetti E 1987 Chemosphere 162225

Carey J H 1990 Proc.-Symp. Adv. Oxid. Processes Treat. Contam. Water Air (Burlington/Ontario: Wastewater Technol. Center) Paper No. 1

Greenberg A E, Trussel R R and Clesceri L S (eds) 1985 Standard methods for the examination of water and wastewater (Washington: Am. Public Health Assoc.) p. 426

Haag W R and Yao C C D 1992 Environ. Sci. Technol. 261005

Hager D G 1990 Innovative Hazard. Wastes Treat. Technol. Ser. 2143 
Hofstadler K 1992 Development of a photocatalytic reactor with immobilized $\mathrm{TiO}_{2}$ for wastewater purification, Doctoral thesis, Technical University, Vienna

Hofstadler K, Ruppert G, Bauer R, Heisler G and Novalic S 1993 In Photocatalytic purification and treatment of water and air (eds) D F Ollis and H Al-Ekabi (Amsterdam: Elsevier) pp. 777-782

Kearney P C, Zeng Q and Ruth J M 1984 ACS Symp. Ser. 259195

Matthews R W 1987 Sol. Energy 38405

Moza P N, Fytianos K, Samanidou V and Korte F 1988 Bull. Environ. Contam. Toxicol. 41678

Ruppert G and Bauer R 1993 J. Photochem. Photobiol. A73 75

Yasuhara A, Otsuki A and Fuwa K 1977 Chemosphere 10659 